\title{
Activation of Glutamate Neurotransmission in the Prefrontal Cortex Sustains the Motoric and Dopaminergic Effects of Phencyclidine
}

\author{
Ryuichi Takahata' and Bita Moghaddam*,' \\ 'Department of Psychiatry, Yale University School of Medicine, West Haven, CT, USA
}

\begin{abstract}
N-methyl-D-aspartate (NMDA) receptor antagonists such as phencyclidine (PCP) produce schizophrenia-like symptoms in healthy individuals, thus generating interest in understanding the mechanisms by which these drugs modify behavior. The hallmark of the behavioral effects of NMDA antagonists in the rodent is stereotyped motor activity. Although the major cellular correlate of this behavioral activation is thought to be an increase in dopamine neurotransmission in the nucleus accumbens (NAc), recent evidence suggests that NAc dopamine is neither necessary nor sufficient to elicit NMDA antagonist-induced motor effects. Based on our previous observation that NMDA antagonists increase glutamate efflux in the prefrontal cortex (PFC), and thus increase non-NMDA receptor glutamatergic neurotransmission in this region, we hypothesized that an increase in PFC efferent activity would activate motor pathways, independent of dopamine neurotransmission in the NAc. We tested this hypothesis by measuring dopaminergic and motoric effects of PCP while blocking non-NMDA receptors in the PFC, or in the ventral tegmental area (VTA) and NAc. Both VTA and NAc receive direct glutamatergic input from the PFC, and are implicated in the regulation of motor behavior. Blocking non-NMDA receptors in the PFC, NAc, or the VTA inhibited PCP-induced locomotion and stereotypy. This blockade was accompanied by an inhibition of PCP's effect on cortical dopamine release. However, the PCP-induced increase in NAc dopamine was not diminished, despite the behavioral inhibition. These findings suggest that the PFC may be a principal site for the regulation of PCP-induced stereotypy and hyperlocomotion, and that this regulation is independent of accumbal dopamine activity.

Neuropsychopharmacology (2003) 28, I I I7-I I24, advance online publication, 26 March 2003; doi: I0. I038/sj.npp. I 300 I 27
\end{abstract}

Keywords: stereotypy; prefrontal cortex; NMDA receptor; locomotion; microdialysis; schizophrenia

\section{INTRODUCTION}

Antagonists of the $N$-methyl-D-aspartate (NMDA) receptor produce a behavioral profile in humans that resembles some aspects of schizophrenia, and therefore have face validity as a pharmacological model of this disorder (Javitt and Zukin, 1991; Tamminga, 1998; Krystal et al, 1999). As would be expected, there is a great deal of interest in defining the cellular and molecular correlates of the behavioral abnormalities associated with these agents because of possible relevance to schizophrenic pathophysiology. In rodents, systemic treatment with NMDA antagonists such as phencyclidine (PCP), MK801, or ketamine produces several behaviors that may be relevant to the 'schizophrenia-like' effects of these drugs in humans (Geyer and Moghaddam, 2002). Some of these behaviors, including disruption of prepulse inhibition and working

\footnotetext{
*Correspondence: Dr B Moghaddam, Department of Psychiatry, Yale University School of Medicine, VA Medical Center 116A/2, West Haven, CT 065 I6, USA, Tel: + I 203932 57 I lext5 I00, Fax: + I 203 937 3829, E-mail: bita.moghaddam@yale.edu

Received 28 February 2002; revised 27 November 2002; accepted 02 December 2002

Online publication: 18 December 2002 at http://www.acnp.org/ Citations/Npp I 2 180244 I
}

memory deficits (Bakshi et al, 1994; Verma and Moghaddam, 1996) are analogous to the effects of these drugs in humans (Krystal et al, 1994; Adler et al, 1998), suggesting that similar mechanisms may subserve these behavioral abnormalities in rodents and humans. For example, excess glutamate neurotransmission at non-NMDA receptors in the prefrontal cortex (PFC) may produce the working memory and other mnemonic effects of these drugs observed in rodents (Moghaddam and Adams, 1998) and humans (Anand et al, 2000).

Another mode of behavioral disruption of NMDA antagonists in the rodent is a distinct pattern of motor behaviors that includes repetitive head and limb movements, and horizontal locomotion (Sturgeon et al, 1979; Sams-Dodd, 1996). NMDA antagonists do not generally produce hyperlocomotion in humans and monkeys; therefore, at first glance, these behaviors may be considered irrelevant to the clinical effects of these drugs. However, because locomotor activity and stereotypy in rodents is generally associated with limbic striatal function, these latter behaviors have been indirectly linked to schizophrenia as a functional expression of limbic abnormalities, which in man may be expressed as psychosis and thought disorder (Matthysse, 1986; Carlsson et al, 1999). This notion has been reinforced by the findings that systemic admin- 
istration of NMDA antagonists increases the release of limbic striatal (ie nucleus accumbens, NAc) dopamine in rodents (Steinpreis and Salamone, 1993; Hertel et al, 1996), consistent with the dopamine hyperactivity hypothesis of schizophrenia (Carlsson, 1978). Nonetheless, it is generally thought that NMDA antagonists produce at least two mechanistically distinct behavioral disruptions, one involving PFC dysfunction leading to cognitive deficits, and the other involving subcortical dopamine hyperactivity leading to stereotypy and hyperlocomotion in rodents and possibly psychosis in man.

Several lines of evidence, however, suggest that dopamine hyperactivity in NAc and other striatal regions may be neither sufficient nor necessary for the motoric effects of NMDA antagonists (Druhan et al, 1996; Cornish et al, 2001). For example, the temporal profiles of dopamine release and motor activation are dissociated (Adams and Moghaddam, 1998; Kretschmer, 2000) and, more importantly, NMDA antagonists produce hyperlocomotion after lesions of dopamine pathways to the NAc (Carlsson and Carlsson, 1989). Considering the profound stimulatory effect of NMDA antagonists on PFC activity in rats (Moghaddam et al, 1997) and humans (Lahti et al, 1995), and the fact that PFC glutamatergic efferents directly innervate regions such as the ventral tegmental area (VTA) that are connected to motor effector sites (Mogensen et al, 1983; Sesack et al, 1989; Groenewegen and Uylings, 2000), we hypothesized that NMDA antagonist-induced increase in PFC activity, in addition to producing the cognitive abnormalities, also underlies the motoric effects of these drugs, independent of NAc dopamine activation.

The NMDA antagonist-induced PFC hyperactivity may be initiated by a disinhibitory mechanism (Grunze et al, 1996) leading to excess glutamate efflux and glutamate-mediated neurotransmission at non-NMDA receptors in the PFC (Moghaddam et al, 1997). Hence, to test the above hypothesis, we investigated the effect of blocking glutamate neurotransmission at non-NMDA receptors by an amino-3hydroxy-5-methylisoxazole-4-propionate (AMPA) antagonist in the PFC, as well as its efferent output regions in the VTA and NAc, on PCP-induced locomotion, stereotypy, and dopamine release in the PFC or NAc.

\section{MATERIALS AND METHODS}

\section{Experimental Design}

All animals used in the study were implanted with one or two microdialysis probes. One probe was placed in the PFC or NAc, and the second in the ipsilateral VTA. Locomotion and stereotypy were assessed during the microdialysis procedure. In some animals, the AMPA receptor antagonist LY293558 was perfused through one of the probes for $2 \mathrm{~h}$, and PCP was injected $1 \mathrm{~h}$ after the initiation of LY293558 perfusion. In control animals, Ringer's solution was perfused throughout the experiment.

\section{Animal Preparation}

All animal procedures were conducted in strict accordance with the NIHGuide for the Care and Use of Laboratory Animals, and were approved by the Yale University Animal
Care and Use Committee. Male Sprague-Dawley rats weighing $280-350 \mathrm{~g}$ were used in this study. Rats were anesthetized with halothane and were placed in a stereotaxic frame with blunt ear bars. An incision was made on the skin over the skull and the wound margin was infiltrated with lidocaine. Holes were drilled for two skull screws and two concentric microdialysis probes were implanted unilaterally in the NAc (AP $+1.8, \pm \mathrm{L} 1.0, \mathrm{~V}-8.4)$ or PFC $(\mathrm{AP}+3.2, \mathrm{~L}$ $\pm 1.6, \mathrm{~V}-6.5$, angle $\left.10^{\circ}\right)$ and the VTA $(\mathrm{AP}-4.8, \mathrm{~L} \pm 1.1, \mathrm{~V}$ -8.4). The coordinates were relative to Bregma and according to the atlas of Paxinos and Watson (1982). The probes were secured in place with dental cement. A thermostatically controlled electric heating pad was used to maintain the body temperature at about $37^{\circ} \mathrm{C}$. Following surgery, animals were allowed to recover for $24 \mathrm{~h}$ before the microdialysis experiment, which was performed in freely moving rats.

\section{Microdialysis Procedure}

Concentric microdialysis probes were constructed with Hospal AN69 polyacrylonitrile dialysis tubing (Renal Care Inc., Lakewood, CO, USA). Their outer diameter was $330 \mu \mathrm{m}$ and their exposed tip measured $2.0-2.5 \mathrm{~mm}$ for NAc, 3.0$3.5 \mathrm{~mm}$ PFC, and $1.0 \mathrm{~mm}$ for VTA probes. Immediately after surgery microdialysis probes were connected by fused-silica tubing to a Harvard syringe pump (Harvard Appartus Co., Holliston, MA, USA). A liquid swivel/balance arm assembly was used (Instech Laboratory Inc., Plymouth Meeting, PA, USA). The perfusion solution contained $145 \mathrm{mM} \mathrm{NaCl}$, 2.7 $\mathrm{mM} \mathrm{KCl}, 1.0 \mathrm{mM} \mathrm{MgCl}_{2}$, and $1.2 \mathrm{mM} \mathrm{CaCl}_{2}$. Probes were perfused overnight at a flow rate of $0.5 \mu \mathrm{l} / \mathrm{min}$ overnight. The flow rate was increased to $2 \mu \mathrm{l} / \mathrm{min}$ the next morning. Dialysate samples were collected every $20 \mathrm{~min}$ and injected immediately onto the HPLC system for the analysis of dopamine.

\section{Chromatographic Analysis}

The content of dopamine in the dialysate was determined by HPLC with electrochemical detection. These HPLC systems used a narrow-bore column $(2.0 \mathrm{~mm}$ inner diameter; $3-\mu \mathrm{m}$ C-18 particles; laboratory packed or obtained from Keystone, Bellefonte, PA, USA) and a Bioanalytical Systems (West Lafayette, IN, USA) LC-4C potentiostat. The $E_{\text {app }}$ was $+0.55 \mathrm{~V}$ vs $\mathrm{Ag} / \mathrm{AgCl}$ reference electrode. The mobile phase consisted of $0.1 \mathrm{M} \mathrm{NaH}_{2} \mathrm{PO}_{4}, 640 \mathrm{mg} / \mathrm{l}$ octylsulfonic acid, 7.2 $\%(\mathrm{v} / \mathrm{v})$ acetonitrile, $0.25 \%$ EDTA, and $350 \mu \mathrm{l} / \mathrm{l}$ of triethylamine, $\mathrm{pH}$ 5.1. HPLC systems with a limit of detection of 2$5 \mathrm{fmol}$ were used for analysis of dopamine.

\section{Locomotion Activity and Stereotypy Rating}

Locomotor activity was recorded during microdialysis measurements and in the animal's home cage, as described before (Adams and Moghaddam, 1998, 2001; Moghaddam and Adams, 1998). This system used four pairs of photocells spaced evenly along the length of the home cage that were connected to a data acquisition system (Med Associates, Inc., St Albans, VT, USA). Nonconsecutive beam breaks were totaled every $20 \mathrm{~min}$. These time intervals were coordinated with the collection periods of the microdialysis 
samples. Stereotypy was rated during microdialysis measurements as previously described (Adams and Moghaddam, 1998). It should be emphasized that our method of assessing horizontal locomotion produces results comparable to those obtained using conventional locomotor chambers (Moghaddam and Adams, 1998; Cartmell et al, 1999), suggesting that the connection of an animal's head to a liquid swivel does not significantly influence the stereotypy and locomotor response to PCP and other pharmacological manipulations.

\section{Drugs and Chemicals}

All reagents for the HPLC mobile phase and the perfusion fluid were of analytical grade and were obtained from JT Baker Chemical Co. (Philipsburg, NJ, USA) and Sigma (St Louis, MO, USA). PCP was a gift from the National Institute of Drug Abuse. LY293558 was a gift from Eli Lilly \& Co. PCP was dissolved in water before use. Stock solutions of LY293558 $\left(10 \mathrm{mM}\right.$ in $\left.\mathrm{H}_{2} \mathrm{O}\right)$ were prepared and kept at $-30^{\circ} \mathrm{C}$ for up to 4 weeks. Before use, stock solutions were diluted in the perfusion solution to a concentration of $100 \mu \mathrm{M}$ for LY293558. This dose of LY293558 produces no effect on basal NAc dopamine and a small decrease in basal dopamine levels in the PFC (Takahata and Moghaddam, 2000).

\section{Data Analysis}

Within-group analysis of the microdialysis data was performed using one-way ANOVA with time as the repeated measures. Comparison of two groups was performed by two-way ANOVA with time as the repeated measures and treatment as the between-group measure. Behavioral data were analyzed by nonparametric Kruskal-Wallis test. The level of significance was set at $p<0.05$. Microdialysis data are presented as a percentage of the mean $( \pm$ SEM) of the three basal values obtained immediately before the drug treatment. The same 'PCP-only' group was used for each main experiment.

\section{Histology}

After the termination of each experiment, animals were anesthetized with chloral hydrate and perfused intracardially with saline followed by $10 \%$ buffered formalin. Brains were removed and stored in formalin. Serial sections of the fixed brains were cut at $250 \mu \mathrm{m}$ intervals and stained with cresyl violet. Probe placement was verified for all the data sets presented in this study.

\section{RESULTS}

\section{Effects of Intra-PFC Application of an AMPA Receptor Antagonist on PCP-Induced Locomotion, Stereotypy, and PFC Dopamine Release}

Figure 1 illustrates the effect of the unilateral intra-PFC application of the AMPA receptor antagonist LY293558 on PCP-induced locomotion, stereotypy, and PFC dopamine release. PCP was injected $(5 \mathrm{mg} / \mathrm{kg}$, i.p.) $1 \mathrm{~h}$ after the initiation of local perfusion of LY293558 $(100 \mu \mathrm{M})$, which continued for $1 \mathrm{~h}$ after the injection. In control animals, PCP
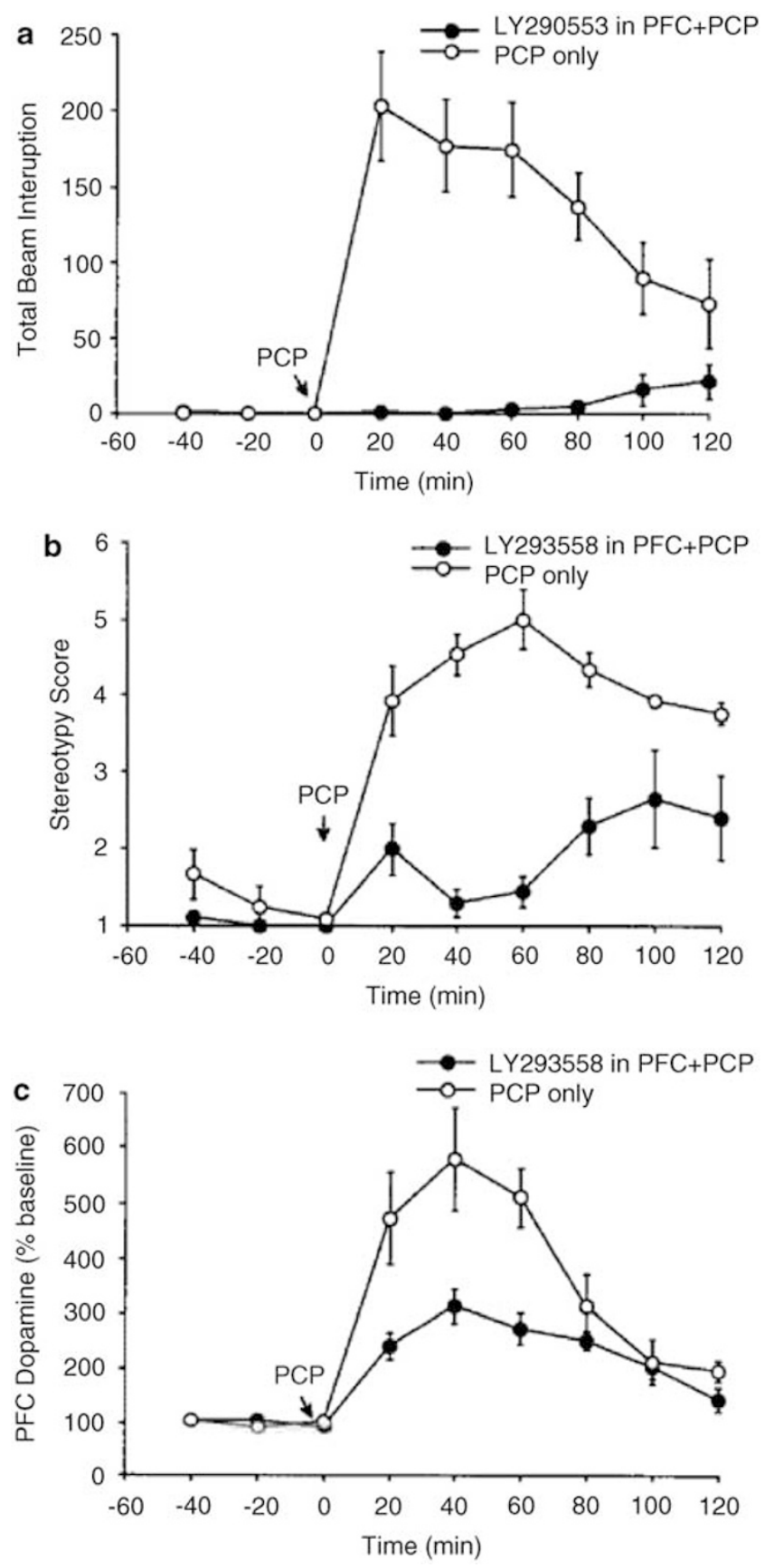

Figure I Effect of intraperitoneal injection of PCP during intra-PFC application of LY293558 on simultaneous measures of locomotor activity, stereotypy, and dopamine release in the PFC. LY293558 (I00 $\mu$ M) was applied to PFC for $2 \mathrm{~h}$. PCP $(5 \mathrm{mg} / \mathrm{kg})$ was injected intraperitoneally I $\mathrm{h}$ after the beginning of LY293558 application. Application of LY293558 to PFC significantly blocked PCP-induced locomotion (a) $(F(8,72)=7.42$, $p<0.00 \mathrm{I})$ and stereotypy (b) $(F(8,72)=5.9 \mathrm{I}, p<0.00 \mathrm{I})$. Administration of PCP increased the dopamine release in $\operatorname{PFC}(F(9,36)=15.25, p<0.001$, $n=5)$. In animals treated with intra-PFC application of LY293558, PCP also increased dopamine release in the PFC $(c)(F(I I, 44)=11.40, p<0.01)$; however, this latter effect was significantly smaller than in animals that received only PCP $(F(8,64)=4.65, p<0.00 \mathrm{I})$. Microdialysis data are expressed as a percentage of baseline (the mean \pm SEM values of three samples before drug application). The average baseline values were $0.18 \pm 0.02 \mathrm{fmol} / \mu \mathrm{l}$ for animals that received LY293558 +PCP $(n=5)$ and $0.22 \pm 0.07 \mathrm{fmol} / \mu \mathrm{l}$ for animals that received only PCP $(n=5)$. 
produced a robust increase in horizontal locomotion (Figure 1a). This effect reached maximum levels $20 \mathrm{~min}$ after the injection and remained elevated for $2 \mathrm{~h}$ after the injection. In contrast, the locomotor activity of animals that were treated with intra-PFC LY293558 did not increase after $\mathrm{PCP}$, resulting in a significant difference between the control and LY293558-treated groups. In addition, the stereotypy produced by PCP was significantly inhibited by intra-PFC application of LY293558, as compared to control animals (Figure 1b). PCP produced the expected large increase in dopamine release, which reached an average maximum level of $580 \%$ above baseline (Figure 1c). In animals treated with LY293558, this activation was significantly attenuated in comparison with control animals.

\section{Effects of Intra-NAc Application of an AMPA Receptor Antagonist on PCP-Induced Locomotion, Stereotypy, and NAc Dopamine Release}

Figure 2 demonstrates the effect of intra-NAc application of the AMPA receptor antagonist LY293558 on locomotion, stereotypy, and dopamine release in this region. Similar to the effect seen after PFC AMPA receptor blockade, application of LY293558 to the NAc inhibited the PCPinduced hyperlocomotion and stereotypy (Figure $2 \mathrm{a}$ and $\mathrm{b}$ ). However, unlike the effect of PFC AMPA receptor blockade, this behavioral inhibition did not generalize to a reduction in PCP-induced accumbal dopamine release; there was no significant difference in the dopaminergic response to PCP in the absence or presence of intra-NAc application of LY293558 (Figure 2c). Thus, the PCP-induced activation of accumbal dopamine release was sustained after intra-NAc application of LY203558 despite the profound behavioral inhibition.

Effects of Intra-VTA Application of an AMPA Receptor Antagonist on PCP-Induced Locomotion, Stereotypy, and PFC and NAc Dopamine Release

In this group of experiments, LY293558 was applied to the VTA through a microdialysis probe while a second probe was used to measure extracellular levels of dopamine in the ipsilateral PFC or NAc. Locomotor activity and stereotypy were assessed during the microdialysis measurements as described above. Application of LY293558 to the VTA significantly attenuated PCP-induced hyperlocomotion and stereotypy (Figure $3 \mathrm{a}$ and $\mathrm{b}$ ). Intra-VTA application of LY293558 also significantly reduced the PCP-induced dopamine increase in the PFC (Figure 3c). However, in contrast to the behavioral inhibition and the effect seen in the PFC, the increase in dopamine release in NAc in response to PCP was not affected after VTA AMPA receptor blockade (Figure 3d).

\section{DISCUSSION}

The present study demonstrates that glutamate neurotransmission in the PFC plays a central role in mediating the effects of PCP on locomotion and stereotypy, and on cortical dopamine release. These effects appear to be mediated, in part, through PFC glutamatergic efferents to the VTA and/or NAc because blockade of AMPA receptors
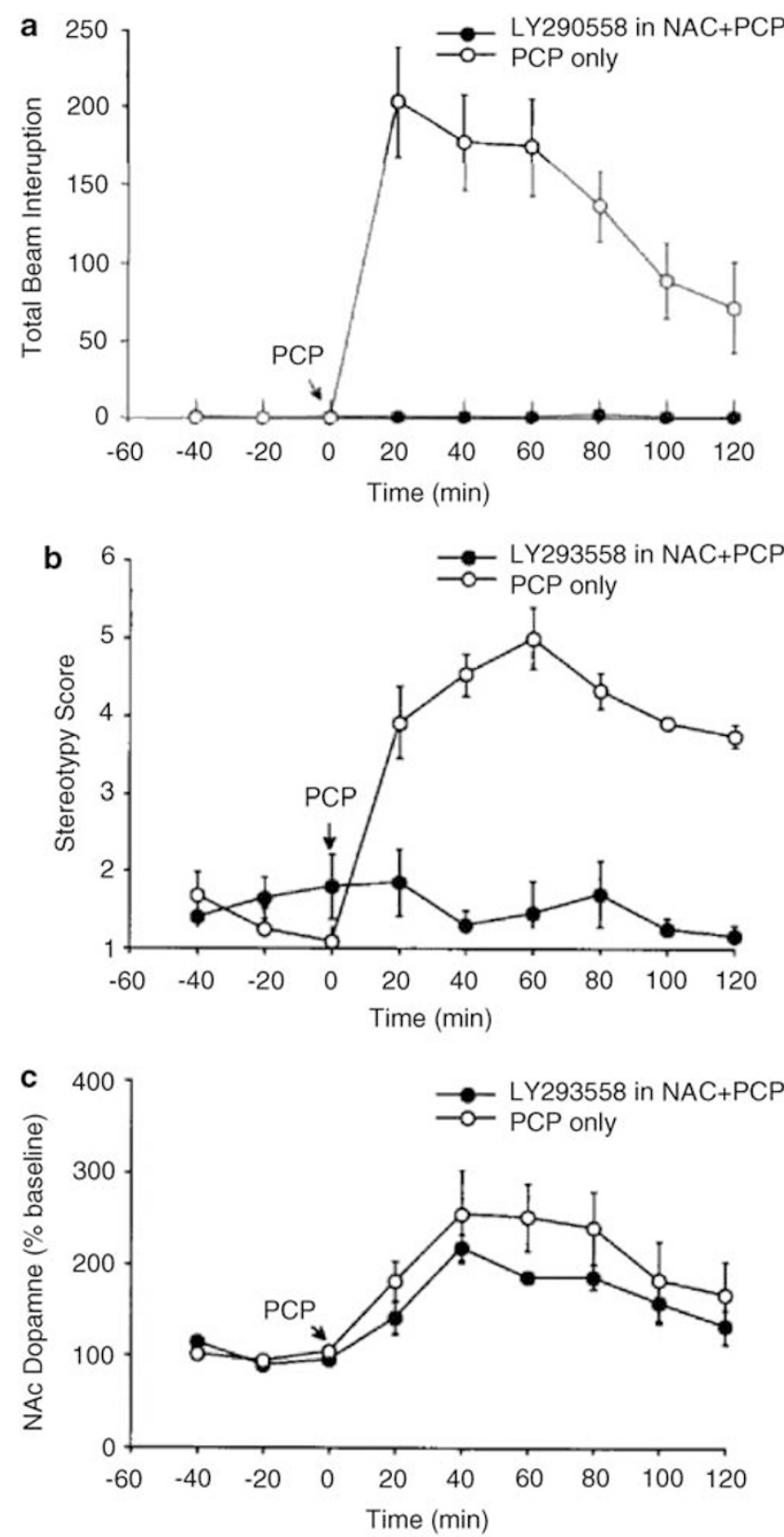

Figure 2 Effect of intraperitoneal injection of PCP during intra-NAc application of LY293558 on simultaneous measures of locomotor activity, stereotypy, and dopamine release in the NAc. LY293558 (I00 $\mu \mathrm{M})$ was applied to the NAc for $2 \mathrm{~h}$. PCP $(5 \mathrm{mg} / \mathrm{kg})$ was injected intraperitoneally I $\mathrm{h}$ after the beginning of LY293558 application $(n=5)$. Application of LY293558 to NAc significantly blocked PCP-induced locomotion (a) $(F(8,72)=8.52, p<0.00 I)$ and stereotypy $(b)(F(8,72)=|6.7|, p<0.00 I)$. Administration of PCP increased the dopamine release in the NAc (c) $(F(9,36)=4.68, p<0.00 \mathrm{I})$. In animals treated with intra-NAc application of LY293558, PCP also increased dopamine release in this region $(F(I I, 44)=11.40, p<0.0 I)$. There was no significant difference between these groups. Microdialysis data are expressed as a percentage of baseline (the mean \pm SEM values of three samples before drug application). The average baseline values were $1.38 \pm 0.20 \mathrm{fmol} / \mu \mathrm{l}$ for animals that received LY293558 + PCP $(n=5)$ and $1.26 \pm 0.34 \mathrm{fmol} / \mu \mathrm{l}$ for animals that received only PCP $(n=5)$.

in these regions also inhibited PCP-induced locomotion and stereotypy. However, in the same animals in which blockade of AMPA receptors inhibited the behavioral effects of PCP, 

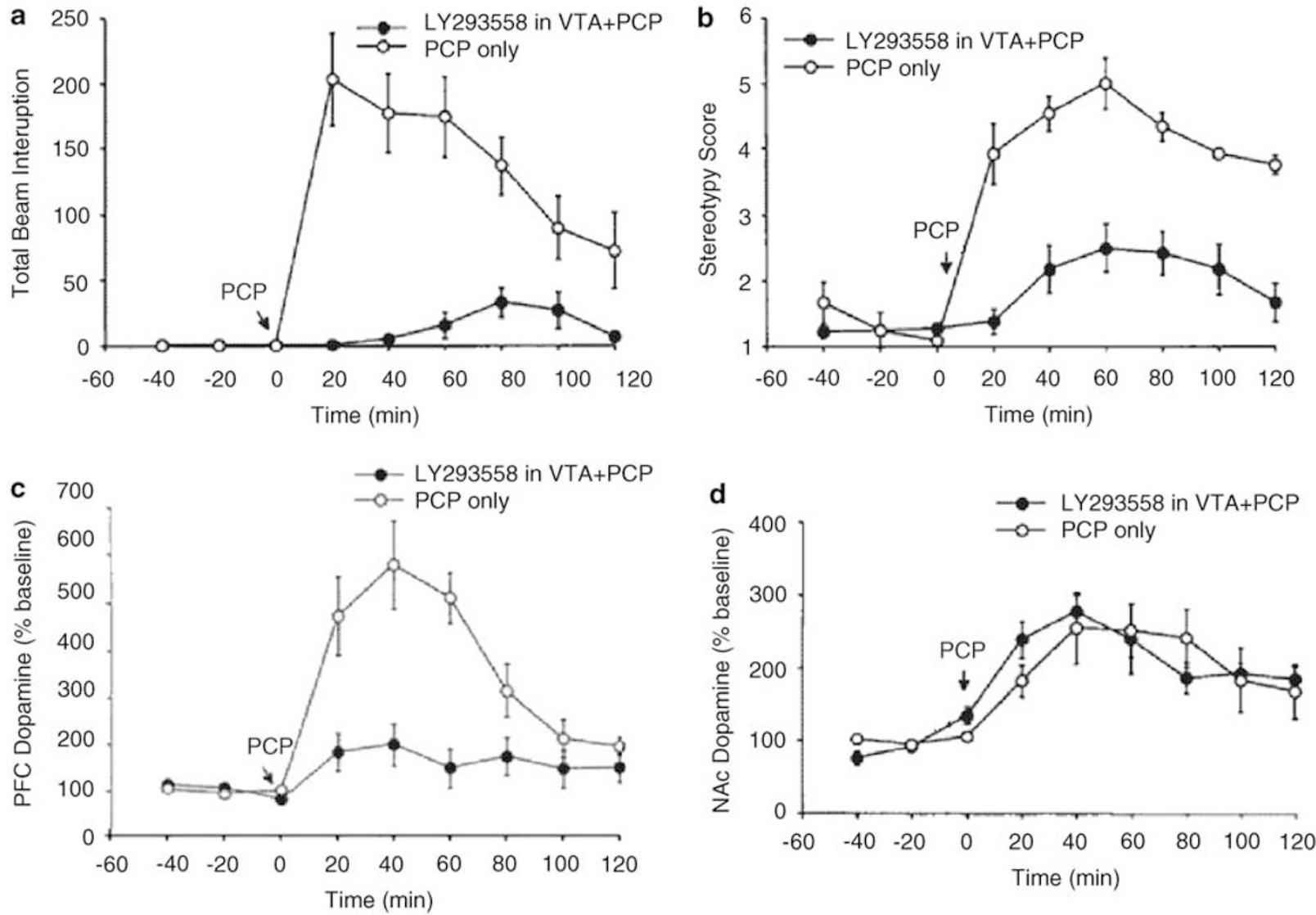

Figure 3 Effect of intraperitoneal injection of PCP during intra-VTA application of LY293558 on simultaneous measures of locomotor activity, stereotypy, and dopamine release in the PFC or NAc. LY293558 (I00 $\mu \mathrm{M})$ was infused to the VTA for $2 \mathrm{~h}$. PCP (5 mg/kg) was injected I h after the beginning of LY293558 application. Application of LY293558 to the VTA significantly blocked PCP-induced locomotion (a) $(F(8,1 \mid 12)=12.18, p<0.001)$ and stereotypy (b) $(F(8, I \mid 2)=13.77, p<0.00 I)$. Administration of PCP increased dopamine release in the PFC $(c)$ of control animals $(F(9,36)=\mid 5.25, p<0.00 I)$ and in animals receiving intra-VTA LY293558 $(F(I), 44)=2.35, p<0.05)$; however, this latter effect was significantly smaller than in animals that received only PCP $(F(8,64)=8.29, p<0.00 I)$. Administration of PCP increased dopamine release in the NAc $(d)$ of control animals $(F(9.36)=4.68, p<0.00 I)$ and animals receiving intra-VTA LY293558 $(F(\mid), 44)=7.91, p<0.001, n=5)$. There was no significant difference between these groups. Microdialysis data are expressed as a percentage of baseline (the mean \pm SEM values of three samples before drug application). In the NAc, the average baseline values were $1.38 \pm 0.20 \mathrm{fmol} / \mu \mathrm{l}(n=5)$ for animals that received only PCP and I.42 $\pm 0.12 \mathrm{fmol} / \mu \mathrm{l}$ for animals that received intra-VTA LY293558 + PCP $(n=5)$. In the PFC, the average baseline values were $0.22 \pm 0.03 \mathrm{fmol} / \mu \mathrm{l}$ for animals that received only PCP $(n=5)$ and $0.18 \pm 0.02 \mathrm{fmol} / \mu \mathrm{l}$ for animals that received LY293558 + PCP $(n=5)$.

activation of accumbal dopamine release by PCP was not attenuated. Thus, PCP-induced locomotion and stereotypy are functionally dissociated from dopamine release in the NAc.

\section{Mechanisms Governing PCP-Induced Behavioral Activation}

Although blockade of the NMDA receptor by PCP is often associated with a general reduction in glutamate-mediated neurotransmission, several lines of evidence suggest that NMDA antagonists, by inhibiting tonic GABA inputs onto cortical or hippocampal pyramidal neurons (Grunze et al, 1996), may also produce a disinhibitory increase in glutamate neurotransmission via non-NMDA receptors in limbic and cortical regions (Liu and Moghaddam, 1995; Moghaddam et al, 1997). This secondary effect is consistent with functional imaging studies in humans treated with ketamine, an analogue of PCP, demonstrating selective cortical metabolic activation after ketamine treatment (Lahti et al, 1995). Hence, PCP and other NMDA antagonists such as MK801 or ketamine may have a dual influence on glutamate neurotransmission that includes an inhibition of NMDA receptors followed by the activation of AMPA and other non-NMDA glutamate receptors.

Previous studies have suggested that activation of nonNMDA receptors mediates some of the behavioral effects of PCP and other NMDA antagonists because pharmacological treatments that reduced glutamate neurotransmission ameliorate hyperlocomotion, stereotypy, and cognitive deficits produced by these drugs (Moghaddam et al, 1997; Mathe et al, 1998; Moghaddam and Adams, 1998). The site of action of this effect, however, is unclear and may depend on the type of behavior. In particular, the PFC has been implicated in the cognitive effects of $\mathrm{PCP}$, the ventral striatum may subserve the motor stereotypy, and the NAc and its projections to motor output areas are thought to regulate the locomotor-activating effects of this drug. The latter hypotheses are supported by an abundance of literature indicating that rodent locomotion and stereotypy are in general supported by NAc and dorsal striatum (Kelly and Iversen, 1976; Mogenson et al, 1980). Furthermore, 
focal application of PCP and other NMDA antagonists such as MK801 and AP5 into the NAc or the VTA produces hyperlocomotion (McCullough and Salamone, 1992; Kalivas and Alesdatter, 1993; Burns et al, 1994; De Leonibus et al, 2001). In addition, lesions or AMPA receptor blockade of motor output targets of the NAc, such as the ventral pallidum or the VTA, block MK801-induced locomotion (Mathe et al, 1998; Cornish et al, 2001; De Leonibus et al, 2001).

Several studies suggest that the PFC may also play a role in NMDA antagonist-induced hyperlocomotion. In particular, intra-PFC application of an NMDA antagonist increases locomotor activity (O'Neill and Liebman, 1987; Feenstra et al, 2002), and lesions of the PFC ameliorate PCPinduced hyperlocomotion (Jentsch et al, 1998). The present study also strongly supports PFC involvement because intra-PFC application of an AMPA antagonist inhibited the effects of PCP on locomotion as well as on stereotypy. The latter effect was especially interesting because stereotypy is generally attributed to dorsal striatal dysfunction (Kelley et al, 1986). To our knowledge, the present findings present the first report implicating PFC involvement in motor stereotypy. As similar behavioral inhibition was observed after AMPA receptor blockade in the VTA or NAc, the PFC involvement could be secondary to the activation of subcortical motor pathways including NAc and VTA, which may influence the activity of glutamate afferents to the PFC via the thalamic feedback loop (eg Groenewegen and Uylings, 2000). However, lesions of mediodorsal thalamus do not affect NMDA-antagonist-induced locomotion (De Leonibus et al, 2001), suggesting that PFC involvement is not secondary to the activation of the NAc, VTA, or other subcortical regions that are connected to the $\mathrm{PFC}$ via the thalamic loop. Considering that the PFC provides a major direct excitatory input to the NAc and VTA (Beckstead, 1979; Sesack et al, 1989), another possible mechanism is that an initial PFC activation increases the activity of its efferents to the NAc and VTA, activating in turn the pathways from these regions to motor output areas. Regardless of the mechanism, our results suggest that although hyperlocomotion and stereotypy are generally associated with striatal abnormalities, a primary deficit in the PFC function can influence motor stereotypy.

\section{Mechanisms Governing PCP-Induced Dopamine Release}

Present microdialysis findings indicate that the NMDA antagonist-induced increase of dopamine release in the PFC is mediated by the activation of glutamate neurotransmission at non-NMDA receptors in the PFC or the VTA. Considering that a major glutamatergic input to the VTA arises from the PFC, but that there are no ascending excitatory projections from the VTA to PFC (Beckstead, 1979; Beckstead et al, 1979; Sesack and Pickel, 1992; Groenewegen and Uylings, 2000), it is plausible to conclude that the activation of glutamatergic efferents from the PFC may lead to an increase in glutamatergic activity in the VTA and stimulation of mesocortical dopamine neurons. This would be consistent with morphological findings showing that PFC projections to the VTA make direct synaptic contact onto dopaminergic neurons that project back to the PFC (Carr and Sesack, 2000a). Hence, the mechanism for
PCP-induced activation of dopamine release in the PFC appears to involve enhancement of glutamate neurotransmission in the PFC and activation of cortico-VTA projections that in turn stimulate mesocortical dopamine neurons in the VTA (Takahata and Moghaddam, 2000).

Although a similar mechanism might be expected in the NAc, our findings suggested otherwise. Specifically, blocking AMPA receptors in the VTA (or NAc) did not affect the PCP-induced increase of accumbal dopamine release. Thus, it appears that different circuitry may govern the activity of mesoaccumbal and mesoprefrontal dopamine neuron located in the VTA (Carr and Sesack, 2000a, b; Takahata and Moghaddam, 2000; Moghaddam, 2002). Specifically, unlike mesocortical dopamine neurons, dopamine neurons that project to the NAc do not appear to receive direct synaptic input from the PFC (Carr and Sesack, 2000a). Therefore, activation of the PFC would not be expected to increase NAc dopamine release. To the contrary, this activation seems to exert an inhibitory control over dopamine release in the NAc (Jackson et al, 2001).

An alternative mechanism that may account for PCPinduced increase in extracellular dopamine in the NAc involves blockade of dopamine transporters by PCP, which, at the dose used here, has a modest affinity for monoamine transporters (Javitt and Zukin, 1991). However, the pattern and magnitude of dopamine release we observed with PCP is similar to that observed for other NMDA antagonists such as ketamine or MK801 (Schmidt and Fadayel, 1996; Verma and Moghaddam, 1996; Feenstra et al, 1998; Mathe et al, 1999), which do not have an affinity for the dopamine transporter at subanesthetic doses.

Another mechanism for the excitatory influence of NMDA antagonists on NAc dopamine release involves inhibition of GABA neurons that project onto mesoaccumbal dopamine neurons. These GABA neurons, which originate primarily in basal ganglia regions including NAc, most likely exert a tonic inhibitory influence on mesoaccumbal dopamine neurons. After treatment with NMDA antagonists, the excitatory cortical drive on these GABA neurons is diminished, leading to disinhibition of dopamine neurons and increased firing activity and synaptic dopamine release. Thus, unlike the mesocortical dopamine neurons, which may be activated by direct cortical excitatory inputs, one mechanism for the mesoaccumbal dopamine neuron activation after PCP treatment may involve a GABA-mediated disinhibitory process. This latter mechanism would account for the lack of effect of intra-VTA (or intra-NAc) application of an AMPA antagonist on PCP-induced dopamine release in the NAc, because the AMPA antagonist would be expected to exacerbate the disinhibitory influence of PCP.

In contrast with the present findings in the NAc, a previous study reported that pretreatment with the AMPA antagonist CNQX reduces the excitatory effects of MK801 on mesoaccumbal dopamine release (Mathe et al, 1998). However, CNQX also has an affinity for the glycine site of NMDA receptors (Mead and Stephens, 1999). Since MK801 acts on open NMDA channels, pretreatment with a glycine site antagonist may reduce the number of open channels and diminish the overall effectiveness of MK801. Another study reported that PFC lesions reduced PCP-induced tissue dopamine turnover in NAc, suggesting that, in contrast to 
the present findings, the PFC regulated PCP-induced activation of accumbal dopamine (Jentsch et al, 1998). However, microdialysis is considered a more reliable method of assessing dopamine neurotransmission than measuring tissue metabolite levels. Furthermore, lesions may produce secondary compensatory mechanisms that may affect tissue monoamine metabolism.

\section{Conclusions and Clinical Implications}

Inhibition of non-NMDA glutamate receptors in the PFC produced a profound attenuation of PCP-induced locomotion and stereotypy. This blockade was accompanied by an inhibition of the effects of PCP on cortical dopamine release. As would be expected, blockade of non-NMDA receptors in the NAc or the VTA, which receive direct glutamatergic input from the PFC, also inhibited the behavioral effects of PCP. However, the PCP-induced increase in NAc dopamine was not diminished during these treatments despite the behavioral inhibition. These findings indicate that the activation of glutamatergic neurotransmission in the PFC plays a major role in motor and cortical dopamine activation by PCP.

The present findings may have relevance for the clinical effects of PCP and possibly schizophrenia. Clearly, functional extrapolation from behavioral effects of PCP in the rodent to symptoms of a complex human disorder such as schizophrenia is highly speculative. Nonetheless, hyperlocomotion in the rodent may be a useful measure of limbic malfunction and the propensity of PCP to produce psychosis in man. Measures of PCP-induced stereotypy may also be clinically relevant because stereotyped tendencies, expressed as repetitive movements or cognitive perseveration, are a common feature of schizophrenia. Although these behaviors are generally associated with subcortical dopamine hyperactivity, the present study suggests that the PFC may be a principal site for the regulation of locomotion and stereotypy. Therefore, a primary defect in the PFC function, especially one involving NMDA receptor dysfunction, may elicit stereotyped behavior and abnormal limbic function independent of subcortical dopamine function.

\section{ACKNOWLEDGMENTS}

This work was supported by PHS awards MH01616, MH48404, and MH44866, and the VA National Center for Schizophrenia.

\section{REFERENCES}

Adams B, Moghaddam B (1998). Corticolimbic dopamine neurotransmission is temporally dissociated from the cognitive and locomotor effects of phencyclidine. J Neurosci 18: 5545-5554.

Adams BW, Moghaddam B (2001). Effect of clozapine, haloperidol, or M100907 on phencyclidine-activated glutamate efflux in the prefrontal cortex. Biol Psychiatry 50: 750-757.

Adler CM, Goldberg TE, Malhotra AK, Pickar D, Breier A (1998). Effects of ketamine on thought disorder, working memory, and semantic memory in healthy volunteers. Biol Psychiatry 43: 811-816.
Anand A, Charney DS, Oren DA, Berman RM, Hu XS, Cappiello A et al (2000). Attenuation of the neuropsychiatric effects of ketamine with lamotrigine: support for hyperglutamatergic effects of $N$-methyl-D-aspartate receptor antagonists. Arch Gen Psychiatry 57: 270-276.

Bakshi VP, Swerdlow NR, Geyer MA (1994). Clozapine antagonizes phencyclidine-induced deficits in sensorimotor gating of the startle response. J Pharmacol Exp Ther 271: 787-794.

Beckstead RJ (1979). An autoradiographic examination of corticocortical and subcortical projections of the mediodorsalprojection (prefrontal) in the rat. J Comp Neurol 184: 43-62.

Beckstead RM, Domesick VB, Nauta WJH (1979). Efferent connections of the substantia nigra and ventral tegmental area in the rat. Brain Res 175: 191-217.

Burns LH, Everitt BJ, Kelley AE, Robbins TW (1994). Glutamatedopamine interactions in the ventral striatum: role in locomotor activity and responding with conditioned reinforcement. Psychopharmacology 115: 516-528.

Carlsson A (1978). Antipsychotic drugs, neurotransmitters, and schizophrenia. Am J Psychiatry 135: 164-173.

Carlsson M, Carlsson A (1989). The NMDA antagonist MK-801 causes marked locomotor stimulation in monamine-depleted mice. J Neural Transm 75: 221-226.

Carlsson A, Waters N, Carlsson M (1999). Neurotransmitter interactions in schizophrenia: therapeutic implications. Biol Psychiatry 46: 1388-1395.

Carr D, Sesack S (2000a). Projections from the rat prefrontal cortex to the ventral tegmental area: target specificity in the synaptic associations with mesoaccumbens and mesocortical neurons. $J$ Neurosci 20: 3864-3873.

Carr DB, Sesack SR (2000b). GABA-containing neurons in the rat ventral tegmental area project to the prefrontal cortex. Synapse 38: $114-123$.

Cartmell J, Monn JA, Schoepp DD (1999). The metabotropic glutamate 2/3 receptor agonists LY354740 and LY379268 selectively attenuate phencyclidine versus D-amphetamine motor behaviors in rats. J Pharmacol Exp Ther 291: 161-170.

Cornish JL, Nakamura M, Kalivas PW (2001). Dopamineindependent locomotion following blockade of $\mathrm{N}$-methyl-Daspartate receptors in the ventral tegmental area. J Pharmacol Exp Ther 298: 226-233.

De Leonibus E, Mele A, Oliverio A, Pert A (2001). Locomotor activity induced by the non-competitive $N$-methyl-D-aspartate antagonist, MK-801: role of nucleus accumbens efferent pathways. Neuroscience 104: 105-116.

Druhan J, Rajabi H, Stewart J (1996). MK-801 increases locomotor activity without elevating extracellular dopamine levels in the nucleus accumbens. Synapse 24: 135-146.

Feenstra MG, Botterblom MH, van Uum JF (1998). Local activation of metabolic glutamate receptors inhibits the handling-induced increased release of dopamine in the nucleus accumbens but not that of dopamine or noradrenaline in the prefrontal cortex: comparison with inhibition of ionotropic receptors. J Neurochem 70: 1104-1113.

Feenstra MG, Botterblom MH, van Uum JF (2002). Behavioral arousal and increased dopamine efflux after blockade of NMDA receptors in the prefrontal cortex are dependent on activation of glutamatergic neurotransmission. Neuropharmacology 42: $752-763$

Geyer M, Moghaddam B (2002). Animal models relevant to schizophrenia disorder. In: Davis KL, Charney C, Coyle JT, Nemeroff C (eds). Psychopharmacology: The Fifth Generation of Progress. Lippincott Williams and Wilkins: Philadelphia.

Groenewegen HJ, Uylings HB (2000). The prefrontal cortex and the integration of sensory, limbic and autonomic information. Prog Brain Res 126: 3-28. 
Grunze HC, Rainnie DG, Hasselmo ME, Barkai E, Hearn EF, McCarley RW et al (1996). NMDA-dependent modulation of CA1 local circuit inhibition. J Neurosci 16: 2034-2043.

Hertel P, Mathe JM, Nomikos GG, Iurlo M, Mathe AA, Svensson TH (1996). Effects of D-amphetamine and phencyclidine on behavior and extracellular concentrations of neurotensin and dopamine in the ventral striatum and the medial prefrontal cortex of the rat. Behav Brain Res 72: 103-114.

Jackson ME, Frost A, Moghaddam B (2001). Stimulation of prefrontal cortex at physiologically relevant frequencies inhibits dopamine release in the nucleus accumbens. J Neurochem 78: 920-923.

Javitt DC, Zukin SR (1991). Recent advances in the phencyclidine model of schizophrenia. Am J Psychiatry 148: 1301-1308.

Jentsch JD, Tran A, Taylor JR, Roth RH (1998). Prefrontal cortical involvement in phencyclidine-induced activation of the mesolimbic dopamine system: behavioral and neurochemical evidence. Psychopharmacology 138: 89-95.

Kalivas PW, Alesdatter JE (1993). Involvement of $N$-methyl-Daspartate receptor stimulation in the ventral tegmental area and amygdala in behavioral sensitization to cocaine. J Pharmacol Exp Ther 267: 486-495.

Kelly PH, Iversen SD (1976). Selective 6OHDA-induced destruction of mesolimbic dopamine neurons: abolition of psychostimulantinduced locomotor activity in rats. Eur J Pharmacol 40: 45-56.

Kelley A, Winnock M, Stinus L (1986). Amphetamine, apomorphime, and investigatory behavior in the rat: analysis of the structure and pattern of responses. Psychopharmacology 88: 66-74.

Kretschmer BD (2000). NMDA receptor antagonist-induced dopamine release in the ventral pallidum does not correlate with motor activation. Brain Res 859: 147-156.

Krystal JH, D'Souza DC, Belge A, Anand A, Charney DS, Aghajanian GK et al (1999). Therapeutic implications of the hyperglutamatergic effects of NMDA antagonists. Neuropsychopharmacology 21: S143-S157.

Krystal JH, Karper LP, Seibyl JP, Freeman GK, Delaney R, Bremner JD et al (1994). Subanesthetic effects of the noncompetitive NMDA antagonist, ketamine, in humans: psychotomimetic, perceptual, cognitive, and neuroendocrine responses. Arch Gen Psychiatry 51: 199-214.

Lahti AC, Holocomb HH, Medoff DR, Tammings CA (1995). Ketamine activates psychosis and alters limbic blood flow in schizophrenia. NeuroReport 6: 869-872.

Liu J, Moghaddam B (1995). Regulation of glutamate efflux by excitatory amino acid receptors: Evidence for tonic inhibitory and phasic excitatory regulation. J Pharmacol Exp Ther 274: 1209-1215.

Mathe JM, Nomikos GG, Blakeman KH, Svensson TH (1999). Differential actions of dizocilpine (MK-801) on the mesolimbic and mesocortical dopamine systems: role of neuronal activity. Neuropharmacology 38: 121-128.

Mathe JM, Nomikos CG, Schilstrom B, Svensson TH (1998). NonNMDA excitatory amino acid receptors in the ventral-tegmental area mediate systemic dizocilpine (MK-801) induced hyperlocomotion and dopamine release in the nucleus accumbens. J Neurosci Res 51: 583-592.

Matthysse S (1986). Animal models in psychiatric research. Prog Brain Res 65: 259-270.

McCullough L, Salamone J (1992). Increases in extracellular dopamine levels and locomotor activity after direct infusion of phencyclidine into the nucleus accumbens. Brain Res 577: 1-9.
Mead AN, Stephens DN (1999). CNQX but not NBQX prevents expression of amphetamine-induced place preference conditioning: a role for the glycine site of the NMDA receptor, but not AMPA receptors. J Pharmacol Exp Ther 290: 9-15.

Mogenson G, Jones D, Yim C (1980). From motivation to action: functional interface between the limbic system and the motor system. Prog Neurobiol 14: 69-97.

Mogensen GL, Swanson LW, Wu M (1983). Neural projections from nucleus accumbens to globus pallidus, substantia innominata, and lateral preoptic-lateral hypothalamic area: an anatomical and electrophysiological investigation in the rat. J Neurosci 3: 189-202.

Moghaddam B (2002). Stress activation of glutamate neurotransmission in the prefrontal cortex: implications for dopamineassociated psychiatric disorders. Biol Psychiatry 51: 775-787.

Moghaddam B, Adams B (1998). Reversal of phencyclidine effects by a group II metabotropic glutamate receptor agonist in rats. Science 281: 1349-1352.

Moghaddam B, Adams B, Verma A, Daly D (1997). Activation of glutamatergic neurotransmission by ketamine: a novel step in the pathway from NMDA receptor blockade to dopaminergic and cognitive disruptions associated with the prefrontal cortex. $J$ Neurosci 17: 2921-2927.

O'Neill KA, Liebman JM (1987). Unique behavioral effects of the NMDA antagonist, CPP, upon injection into the medial pre-frontal cortex of rats. Brain Res 435: 371-376.

Paxinos G, Watson C (1982). The Rat Brain in Stereotaxic Coordinates. Academic Press: New York.

Sams-Dodd R (1996). Phencyclidine-induced stereotyped behaviour and social isolation in the rat: a possible animal model of schizophrenia. Behav Pharmacol 7: 3-23.

Schmidt CJ, Fadayel GM (1996). Regional effects of MK-801 on dopamine release: effects of competitive NMDA or 5-HT2A receptor blockade. J Pharmacol Exp Ther 277: 1541-1549.

Sesack S, Deutch A, Roth R, Bunney B (1989). Topographical organization of the efferent projections of the medial prefrontal cortex in the rat: an anterograde tract-tracing study with Phaseolus vulgaris leucoagglutinin. J Comp Neurol 290: 213-242.

Sesack S, Pickel V (1992). Prefrontal cortical efferents in the rat synapse on unlabeled neuronal targets of catecholamine terminals in the nucleus accumbens septi and on dopamine neurons in the ventral tegmental area. J Comp Neurol 320: 145160 .

Steinpreis R, Salamone J (1993). The role of nucleus accumbens dopamine in the neurochemical and behavioral effects of phencyclidine: a microdialysis and behavioral study. Brain Res 612: 263-270.

Sturgeon R, Fessler R, Meltzer H (1979). Behavioral rating scales for assessing phencyclidine-induced locomotor activity, stereotyped behavior and ataxia in rats. Eur J Pharmacol 59: 169-179.

Takahata R, Moghaddam B (2000). Target-specific glutamatergic regulation of dopamine neurons in the ventral tegmental area. $J$ Neurochem 75: 1775-1778.

Tamminga CA (1998). Schizophrenia and glutamatergic transmission. Crit Rev Neurobiol 12: 21-36.

Verma A, Moghaddam B (1996). NMDA receptor antagonists impair prefrontal cortex function as assessed via spatial delayed alternation performance in rats: modulation by dopamine. $J$ Neurosci 16: 373-279. 